\title{
Constrictive Pericarditis in Childhood
}

\author{
A. SIMCHA ${ }^{\star}$ and J. F. N. TAYLOR
}

\begin{abstract}
Simcha, A., and Taylor, J. F. N. (1971). Archives of Disease in Childhood, 46, 515. Constrictive pericarditis in childhood. Five children with constrictive pericarditis are described. All underwent surgery to release the restricted heart, and two died.

Tuberculosis still plays a major role in the aetiology of this disease; it was proven in one patient and suspected in two others. No other aetiological factors were identified.

Clinically, constrictive pericarditis does not differ from the disease described in adults.

Protein-losing enteropathy as a result of the constricted pericardium was present in the youngest patient in this series.

The degenerative changes taking place in the myocardium, secondary to the pericardial involvement, mainly determine the outcome of surgery. Pericardiectomy and decortication of the constricted pericardium should be performed without delay, as soon as this diagnosis is established.
\end{abstract}

Constrictive pericarditis is an uncommon disease: Wood (1961) described only 40 patients and only 53 patients were seen in the Massachusetts General Hospital between 1914-1947 (Paul, Castleman, and White, 1948). However, because of its protean manifestations there is much literature on the subject.

Constrictive pericarditis is even less common in childhood, and is very rare under the age of 10 years. Consequently published reports from even the large paediatric centres relate to only small numbers of children (Keith, Rowe, and Vlad, 1967; Nadas, 1966; Shea, Kirklin, and DuShane, 1957).

This report contains the experience of the 5 cases seen in this hospital during the past 18 years.

\section{Subjects}

Five patients under 15 years of age were diagnosed as having constrictive pericarditis here between 19521970. The diagnosis was confirmed at operation in all. Additionally, 32 patients with pericardial effusion, with pericarditis, or with tamponade were seen during the same period; in none of these had constrictive pericarditis developed.

Of the 5 patients in this series, 4 were over 10 years of age, and the fifth was 2 years old at the time of operation. 3 patients were male, 2 female.

Received 22 March 1971.

$\star$ Morrison Foundation Fellow, Thoracic Unit, The Hospital for Sick Children, Great Ormond Street, London.
Clinical features. The duration of ill health before diagnosis was less than 6 months in the 3 boys. Abdominal distension and ascites were present for 2 and 5 years in the 2 girls. In one of these latter patients an appendicectomy had been carried out at the onset of the illness without improvement in her symptoms. One boy was found to have hepatosplenomegaly at a routine school medical examination.

Exercise tolerance was limited in all patients by fatigue and exertional dyspnoea. Ascites developed in all patients also, and required paracentesis. One patient developed oedema and a protein-losing enteropathy.

No patient gave a history suggestive of previous acute pericarditis.

In this series previous tuberculous infection could only be substantiated in one case; the Mantoux test was positive and calcified abdominal lymph nodes were seen in plain $x$-rays. In a second patient however the fluorescent technique indicated probable mycobacteria in the removed pericardium, though the Mantoux test was negative, as were the results of bacterial culture techniques. In a third patient giant cell systems were shown histologically in the pericardium but there was no other evidence of a tuberculous infection. In the remaining 2 cases the aetiology was undetermined.

Physical findings. All patients had a high jugular venous pressure. Paradoxical arterial pulsation was noted in 3. The praecordium was quiet and the heart sounds faint in all patients. No murmurs were heard, but there was a third heart sound in 2. The liver was enlarged and firm, being found more than $10 \mathrm{~cm}$ below 
the costal margin in 2 patients. The spleen was palpable in 3. Ascites was a constant finding, and 3 patients had pleural effusions. Peripheral oedema was found in only one patient.

ECG. First degree AV dissociation was found in one patient, the rest had sinus rhythm. Low voltage QRS complexes were seen in all leads, with ST segment depression in the praecordial leads. One patient showed left ventricular hypertrophy. In only 2 patients did the ECG alter after operation, with increased QRS complex voltage and reversal of the $T$ wave pattern.

Chest $x$-ray findings. A small heart shadow was seen in 1 patient only. 2 patients had normal cardiac silhouettes and the remaining 2 showed enlargement.

Calcification (Fig. 1) was not always visible in the plain $x$-ray, even in the lateral view, but was seen in all but one patient by screening with the image intensifier. (This patient was found at subsequent operation to have a calcified pericardium.) Limited cardiac pulsation was observed in 4 patients.

Laboratory findings. The blood count was always normal; the ESR was between 1-8 mm/hr. Serum electrolytes, blood urea, and conventional liver function were normal, except the prothrombin time which was abnormal in all. In one patient with oedema, hypoproteinaemia due to a protein-losing enteropathy was present with repeated protein levels of $2-2.5 \mathrm{~g} / 100 \mathrm{ml}$ despite repeated infusions of salt-free albumin.

In 2 patients radiochromium studies failed to demonstrate any protein loss through the intestinal wall.

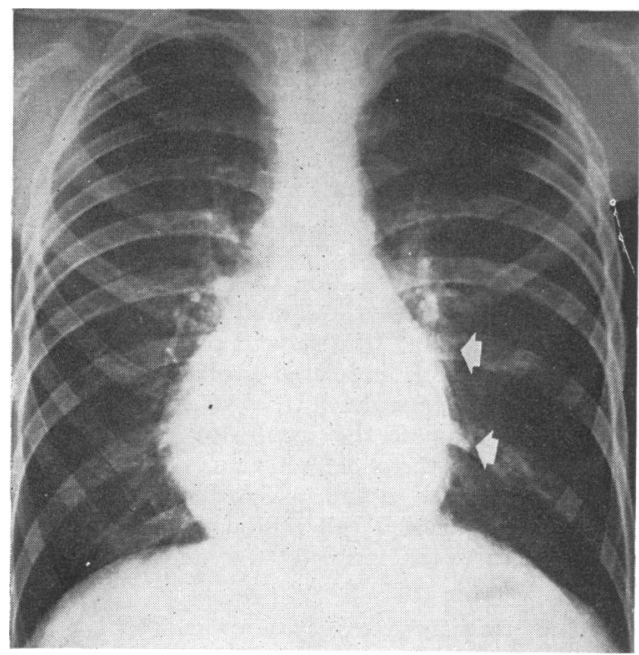

FIG. 1.-Posteroanterior chest $\mathrm{x}$-ray of a boy of 10 , successfully operated, showing enlargement of the right atrium, and some prominence of the superior vena cava; calcification is visible over the ventricular parts of the heart.
In 2 other patients liver biopsy was performed, nonspecific inflammatory change with minimal fibrosis in one case being the only lesion found.

Catheterization data. Four patients were fully investigated. In the fifth patient only the cubital venous pressure was measured and found to have a mean of $15 \mathrm{mmHg}$. The right atrial, right ventricular end-diastolic pressures were similar in all 4 patients, the mean right atrial pressure being $23 \mathrm{mmHg}$, as were the mean end-diastolic and right ventricular pressures (Fig. 2).

Treatment. Antituberculous therapy was started before operation in all cases. It was discontinued postoperatively when tuberculosis could be excluded after bacteriological and histological study of the removed pericardium. Pericardial biopsy, prior to pericardiectomy was undertaken in only the youngest patient as the clinical diagnosis was not entirely clear. All patients had a partial pericardiectomy and decortication through a median sternotomy incision.

\section{Results}

One patient died at operation and one patient died 14 hours after operation being unable to maintain an adequate cardiac output. At necropsy the latter had severe atrophy, and degeneration of myocardial fibres involving both ventricles was found.

Of the 3 survivors, the outcome has been very good with no complications and without residual symptoms. Venous pressure has remained high, but hepatomegaly has regressed and ascites disappeared. Calcification in the part of the pericardium not removed is still evident on $x$-ray examination in one patient.

\section{Discussion}

This small series confirms previous observations regarding the rarity of constrictive pericarditis in childhood. The incidence of the disease within the spectrum of heart disease seen in this centre is about $0.05 \%$, and is $13 \%$ of all the cases treated here for pericarditis.

Roshe (Roshe and Shumacker, 1959) collected from the literature, up to 1959, only 68 children under 15 years of age, who underwent pericardiectomy for constrictive pericarditis and pericardial effusion. 14 of these children were under 10 years of age, and in this series only 1 out of the 5 patients was under 10 years. It is well documented by other authors (Neill and Haroutunian, 1968) that the incidence increases after the first decade of life.

Constrictive pericarditis is regarded as pre- 


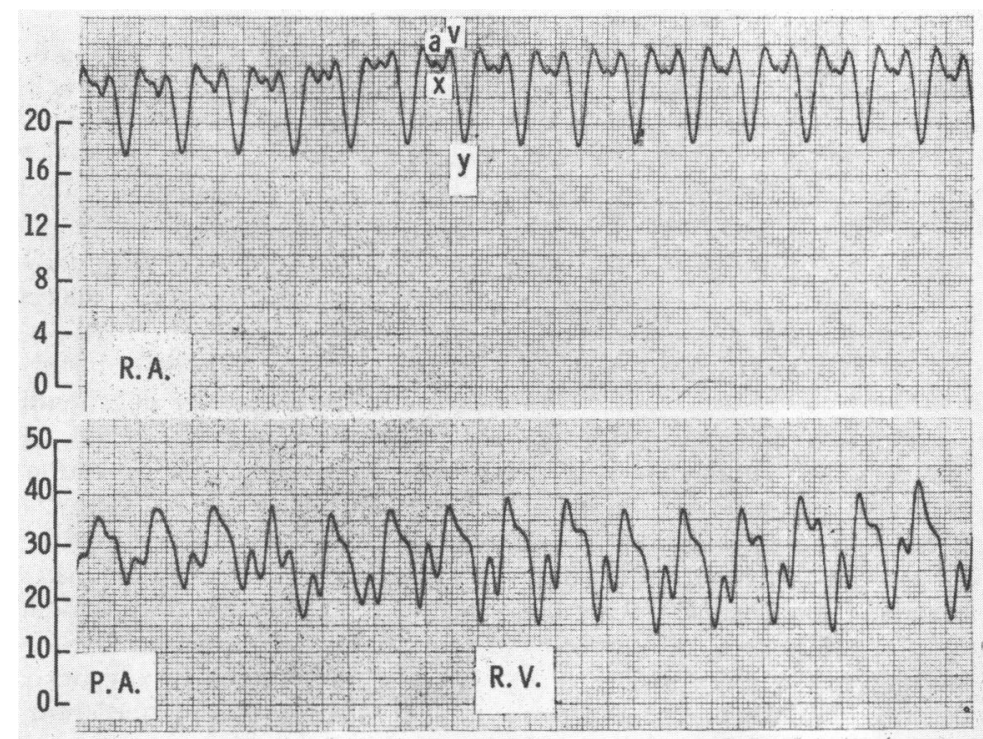

FIG. 2.-Haemodynamic findings in a girl of 13, taken before operation. Lower trace: note the increase in right ventricular end-diastolic pressure. Upper trace: right atrial tracing illustrates high $A$ and $V$ waves and a prominent $Y$ descent.

dominantly a male disease. Andrews (Andrews, Pickering, and Sellors, 1948) found almost $80 \%$ of his patients to be male. Though most of the series published, including the present one, are not large, and do not consist of more than 5 to 8 cases, there is a male predominance in all series.

Tuberculosis plays a major role in the aetiology of constrictive pericarditis; strong evidence for this is found in this series. One patient had a strongly positive Mantoux test and calcified abdominal glands, in another acid-fast bacilli were identified in the removed pericardium, while in the third case the evidence was suggestive.

Rheumatic fever, which is the predominant cause of pericardial involvement in heart disease in children, hardly ever leads to constrictive pericarditis, and this is held to be the explanation for the rarity of constrictive pericarditis in childhood (Cayler and Riley, 1968).

More and more viruses are recognized as the agents causing pericarditis in infants and children (Kagan and Bernkopf, 1957), yet there were few reports of constrictive pericarditis developing after viral pericarditis (Gibbons, Goldbloom, and Dobell, 1965). No evidence for viral infection was established in this series.

White (1951) expressed his belief that virtually all cases of chronic pericarditis are the result of previous tuberculous pericarditis, which in most instances has gone unrecognized. A clinical history of tuberculosis was not found in this series even when laboratory evidence for tuberculosis was substantiated.

The spectrum of symptoms in childhood is similar to that in adults. Abdominal distension was described as the most common presenting symptom; oedema, when present, is far less striking than abdominal distension, and in this series was only present in one patient who had a proven protein-losing enteropathy. Shortness of breath and dyspnoea at rest were encountered less frequently in this series, but were serious when they occurred.

The classical triad of signs in constrictive pericarditis as described by Beck (1935) is ascites, high venous pressure, and a quiet heart (manifested either by decreased praecordial activity or by diminished pulsation on fluoroscopy). The first two criteria were consistently demonstrated, but the third was found in only 4 of the 5 patients.

Calcification on $x$-ray examination is suggestive of constrictive pericarditis, but the absence of visible calcification does not exclude the diagnosis. This is best demonstrated in the lateral and obique views, but was evident as well in the posteroanterior view in some patients. Calcification was observed in 4 of the 5 patients.

The ECG is one of the valuable preliminary diagnostic aids available in the study of this disease. The typical changes are QRS complexes of low 
amplitude in both standard and unipolar leads, with low amplitude or inverted $T$ waves. These changes were recorded in all our patients. ECG changes after pericardiectomy have no prognostic significance (Somerville, 1968), do not follow any certain pattern, and do not reflect the completeness of operation. Among the 3 survivors in this series, 2 showed obvious improvement in their ECG tracings after operation.

Although atrial fibrillation is described commonly in patients with constrictive pericarditis, it was not experienced in this series.

Cardiac catheterization is a valuable procedure in the study of patients in whom constrictive pericarditis is suspected. There is excellent correlation between the physiopathological changes occurring in this disease and the haemodynamic findings. Inflow stasis and low cardiac output are the main physiological sequelae of the calcified pericardium, and the inability of the heart muscle to expand normally during diastole, and to contract during systole. Because of the inability of the heart to expand during diastole, ventricular end-diastolic pressures are raised. Pulmonary artery diastolic pressures and the right ventricular end-diastolic pressures in our investigated cases resembled the right atrial mean pressure, all being significantly raised. Peripheral artery systolic pressures are reported to be low in constrictive pericarditis, but none of the children described in this series had a significant variation from the normal.

Hypoproteinaemia and transient or persistent proteinuria are both common in right heart failure regardless of the cause and are often reported in constrictive pericarditis. Hypoproteinaemia may also be the result of impaired liver function or due to loss of protein in the urine or the ascitic fluid. In this series proteinuria was not found and the serum protein levels in a!l except one patient were normal.

In this patient with a protein-losing enteropathy the liver function tests were impaired, and there was a very low serum protein level, persisting despite albumin infusions.

Gastrointestinal signs are common in constrictive pericarditis, and lymphatic congestion of the intestine as a result of the impaired venous return can occasionally give rise to loss of protein through the intestinal wall. Therefore constrictive pericarditis should be considered in cases of obscure protein-losing enteropathy. Though unusual, 10 such cases have been reported (Plauth et al., 1964), and it seems that this complication occurs relatively more often in young patients.

The treatment in all cases is operation, by partial pericardiectomy and decortication. This is the only procedure that can relieve the heart muscle from its restriction and allows it to resume normal function, but the outcome is influenced by the condition of the myocardium at the time of the decortication.

Constrictive pericarditis is a disease which involves more than the two layers of the pericardium. More or less extensive degenerative change of the underlying myocardium takes place (Dines, Edwards, and Burchell, 1958), and it is the extent of this damage that determines the eventual outcome. The degree of degeneration is partly timedependant (Somerville, 1968) and thus once the diagnosis is established operation should be undertaken promptly. It is essential to decorticate the heart, i.e. remove the visceral pericardium as well as the parietal layer. This may be difficult as it is bound to the myocardium which may have become abnormally thin and friable. a fact that makes operative treatment in advanced cases hazardous.

The total results of operation vary a great deal and the operative and postoperative mortality ranges in different series from 4 to $45 \%$ (Portal et al., 1966; Dayem et al., 1967), but the overall results in children have been satisfactory (Roshe and Shumacker, 1959). Of the two deaths in this series, one operative death was purely accidental, due to air embolism; the other death was postoperative and due to severe myocardial atrophy.

The authors are grateful to Mr. D. J. Waterston and Mr. E. Aberdeen, who performed the operations; to Dr. R. A. Risdon, for the histology; and to Dr. R. E. Bonham-Carter for encouragement and help in the preparation of this paper.

\section{REFERENCES}

Andrews, G. W. S., Pickering, G. W., and Sellors, T. H. (1948) The aetiology of constrictive pericarditis, with special reference to tuberculous pericarditis, together with a note of polyserositis. Quarterly fournal of Medicine, 17, 291.

Beck, C. S. (1935). Two cardiac compression triads. Fournal of the American Medical Association, 104, 714.

Cayler, G. G., and Riley, H. D., Jr. (1968). In Heart Disease in Infants, Children and Adolescents, p. 860 . Ed. by A. J. Moss and F. H. Adams. Williams and Wilkins, Baltimore.

Dayem, M. K. A., Wasf, F. M., Bentall, H. H., Goodwin, J. F., and Cleland, W. P. (1967). Investigation and treatment of constrictive pericarditis. Thorax, 22, 242.

Dines, D. E., Edwards, J. E., and Burchell, H. B. (1958). Myocardial atrophy in constrictive pericarditis. Proceedings of the Staff Meetings of the Mayo Clinic, 33, 93.

Gibbons, J. E., Goldbloom, R. B., and Dobell, A. R. C. (1965). Rapidly developing pericardial constriction in childhood following acute nonspecific pericarditis. American fournal of Cardiology, 15, 863.

Kagan, H., and Bernkopf, H. (1957). Pericarditis caused by coxsackie virus B. Annales Paediatrici, 189, 44.

Keith, J. D., Rowe, R. D., and Vlad, P. (1967). Heart Disease in Infancy and Childhood, 2nd ed., p. 986. Macmillan, New York; Collier-Macmillan, London.

Nadas, A. S. (1966). Pediatric Cardiology, 2nd ed., p. $305 . \quad$ W. B. Saunders, Philadelphia and London. 
Neill, C. A., and Haroutunian, L. M. (1968). Paediatric Cardio$\log y$, p. 722. Ed. by H. Watson. Lloyd-Luke, London.

Paul, O., Castleman, B., and White, P. D. (1948). Chronic constrictive pericarditis: a study of 53 cases. American fournal of the Medical Sciences, 216, 361.

Plauth, W. H., Jr., Waldmann, T. A., Wochner, R. D., Braunwald, N. S., and Braunwald, E. (1964). Protein-losing enteropathy secondary to constrictive pericarditis in childhood. Pediatrics, 34, 636.

Portal, R. W., Besterman, E. M. M., Chambers, R. J., Sellors, T. H., and Somerville, W. (1966). Prognosis after operation for constrictive pericarditis. British Medical fournal, 1, 563.

Roshe, J., and Shumacker, H. B., Jr. (1959). Pericardiectomy for chronic cardiac tamponade in children. Surgery, 46, 1152.
Shea, D. W., Kirklin, J. W., and DuShane, J. W. (1957). Chronic constrictive pericarditis in children. American fournal of Diseases of Children, 93, 430.

Somerville, W. (1968). Constrictive pericarditis. Circulation, Vol. 37-38, Suppl. 5, 104.

White, P. D. (1951). Chronic constrictive pericarditis. Circulation, 4, 288.

Wood, P. (1961). Chronic constrictive pericarditis. American fournal of Cardiology, 7, 48.

Correspondence to R. E. Bonham-Carter, The Thoracic Unit, The Hospital for Sick Children, Great Ormond Street, London WC1N 3JH. 